\title{
欲-
}

\section{Uso y desuso del capital social comunitario: Algunos hallazgos y reflexiones desde un barrio periférico de León de Nicaragua}

\author{
Julio Argueta Jaen \\ DEPARTAMENTO DE TRABAJO SOCIAL \\ FACULTAD DE CIENCIAS DE LA EDUCACIÓN Y HUMANIDADES \\ UNIVERSIDAD NACIONAL AUTÓNOMA DE NICARAGUA, LEÓN (UNAN-LEÓN) \\ julioarguetajaen@hotmail.es
}

Resumen: Este artículo analiza el capital social comunitario en el reparto ${ }^{1}$ San Jerónimo de la ciudad de León, Nicaragua. Este barrio es uno de los más antiguos de la periferia norte de la ciudad con bajos niveles de progreso social en relación a otros barrios que surgieron con posterioridad al mismo. A partir de una investigación realizada en 2010 , en el artículo se desarrollan tres aspectos: 1.- Un vistazo general al recorrido y construcción del concepto de capital social. De seguido se presenta la perspectiva analítica adoptada y la descripción de cómo operacionalmente fue realizado el estudio; 2.- Identificación, análisis y valoración sintética de los principales indicadores de capital social, así como de los factores que limitan su desarrollo. De igual forma se valora el nivel de capital social y las posibilidades de mejorar los indicadores analizados; 3.- Algunas interrogantes y reflexiones respecto al uso y las potencialidades del capital social.

${ }^{1}$ Suele llamársele a los barrios que se localizan en la periferia de las ciudades. 
Palabras claves: Capital social comunitario, perspectivas analíticas, dimensiones, medición, politización, experiencias precursoras y relaciones de causalidad del capital social.

\title{
Use and disuse of community social capital: Some findings and reflections from a suburb of León in Nicaragua
}

\begin{abstract}
This article analyses the community social capital in the San Jerónimo district of the city of León in Nicaragua. This neighbourhood is one of the oldest on the northern side of the city, with low levels of social progress in relation to other districts that developed at a later date. Taking the research from a study carried out in 2010 as the starting point, this article examines three aspects: 1.- An overview of the trajectory and construction of the concept of social capital. The analytical perspective adopted is then presented, along with a description of how the study was conducted in operational terms; 2.- Identification, analysis and synthetic evaluation of the main indicators of social capital, together with the factors that limit its development. Likewise, the level of social capital is also assessed, along with the chances of improve the indicators analysed. 3.- Some questions and thoughts regarding the use and potential of social capital.
\end{abstract}

Key Words: Community social capital, analytical perspectives, dimensions, measurement, politicisation, precursor experiences and relationships of casuality of the social capital.

Agradezco el apoyo, la revisión, comentarios y críticas que realizara el Prof. Ángel Sanz Cintora².

${ }^{2}$ Maestro, colega, militante de causa y particular amigo de la Universidad de Zaragoza. Por su consagración y valiosa colaboración en la fundación y desarrollo de nuestra carrera de Trabajo Social, el 26 de junio de 2012 fue nombrado Profesor Honorario de la UNAN-León. 


\section{Uso y desuso del capital social comunitario:}

\section{Algunos hallazgos y reflexiones desde un barrio periférico de León de Nicaragua}

Julio

Argueta Jaen

RECIBIDO: $14 / 07 / 2012$

ACEPTADO: 22/11/2012

En las ciencias sociales diversas perspectivas teóricas permiten aproximarnos al reconocimiento e interpretación de la problemática social. Pero más importante aún es la capacidad de respuestas que, a partir de la investigación de los hechos, se pueden generar y poner en práctica para enfrentar los complejos desafíos de las sociedades humanas.

Para dar lugar a esto es fundamental el análisis de la interacción social que se realiza en los distintos espacios, niveles y dimensiones sociales, con lo que para facilitar procesos de transformación social efectivos y sostenibles, hay que modificar los determinantes macro estructurales que condicionan el desarrollo humano, pero también es necesario un cambio en las relaciones que se producen a escala micro en la cotidianeidad. Es a esto lo que Forsthoff, referido por Montoro (1997: 37), llama espacio vital dominado por las personas. En este sentido, el espacio al que nos referimos en este trabajo es al vecindario. En esta lógica, Viteri Díaz (2006: 17-19) relacionando a Kingsley, McNeely y Gibson, señala que para generar desarrollo, entre otras cosas, hay que apoyarse en los activos que se poseen y, como agrega Kliksberg, entre estos activos está el capital social (Arboleda, Ghiso y Quiroz, 2008: 78). 


\section{ALGUNOS ANTECEDENTES DEL CAPITAL SOCIAL}

Examinando los orígenes del término encontramos que, para Antoine Bevort (2007, p: 1), el capital social no es una innovación sociológica. Esta noción está presente de una u otra forma en los textos de los fundadores del pensamiento sociológico, por ejemplo, en la tradición iniciada por Tocqueville y su atención al rol de las asociaciones en la democracia estadounidense. Más tarde Max Weber prolonga esa tradición con sus trabajos sobre las sectas religiosas en ese país. Bevort afirma que Weber encuentra que la pertenencia a grupos religiosos es un asunto casi siempre presente en la vida social o profesional de los ciudadanos y de esto dependen en gran medida las relaciones duraderas y la buena reputación. La admisión en una comunidad religiosa equivalía a gozar de una garantía de probidad moral, esto favorecía la integración social y el éxito económico; lo contrario, la exclusión, significaba una pérdida de crédito en negocios y un desplazamiento social.

En los trabajos de Durkheim hay referencias a la unión social y las formas de solidaridad. Así encontramos que, en su análisis de los fundamentos de la solidaridad, refería:

"Si la división del trabajo produce solidaridad, no es sólo porque convierte a cada individuo en un cambista como dicen los economistas; es porque crea entre los hombres todo un sistema de derechos y deberes que nos unen los unos a los otros de manera duradera".

Durkheim llegó a establecer dos tipos de solidaridad, la mecánica y la orgánica. La primera, más espontánea, típica de los primeros estadíos sociales y la segunda, más organizada, propia de las sociedades modernas pero ambas caracterizadas por interrelaciones de cooperación y reciprocidad (Light, Keller \& Calhoun, 1991: 18-19).

Otro antecedente clásico del término es el de Marx, el que referido por Portes (1998: 249), vincula la solidaridad a la conciencia de clase del proletariado. En este sentido Marx dijo:

Al verse arrojados a una situación común, los trabajadores aprenden a identificarse mutuamente y cada uno apoya las iniciativas de los otros. Esta solidaridad no es resultado de una introyección de normas durante la infancia, sino pro- 
ducto emergente de un destino común. Por esta razón, en estas situaciones las disposiciones altruistas de los actores no son universales, están circunscriptas a los límites de la comunidad.

En esta misma lógica se inscriben los planteamientos antropológicos sobre capital social. Arriagada (2003: 6), señala que en los escritos de Firth, Mauss y Foster hay referencias al término, a modo de señalar a la organización social como relaciones y redes de reciprocidad y de intercambios que generan instituciones y estructuras sociales.

\section{PRIMERAS EXPLICACIONES SOBRE EL CAPITAL SOCIAL CONTEMPORÁNEO}

Forni, Siles y Barreiro (2004: 2), refieren a Wallis, Killerby y Dollery para atribuir a Lyda Judson Hanifan ser el precursor en el uso del término. Éste, en 1916 argumentó que:

El desempeño de las escuelas locales podía mejorarse a partir de aquellas sustancias tangibles que cuentan más en la vida diaria de las personas: específicamente buena voluntad, compañerismo, empatía y el encuentro social entre individuos y familias que construyen una unidad social... Si los individuos entran en contacto con sus vecinos, y ellos con otros vecinos, habrá una acumulación de capital social que puede satisfacer sus necesidades sociales y puede producir un potencial social suficiente para realizar una mejora de las condiciones de vida en toda la comunidad.

Woolcock y Narayan (p. 4), sostienen que después de Hanifan la idea del capital social desapareció por varias décadas. No obstante, sin mayores repercusiones, de alguna manera fue reinventado en los años cincuenta por los sociólogos canadienses Seely, Sim y Loosely (1956). En los sesenta lo retomaron Homans y Jacobs, el primero teórico del intercambio y el segundo académico de temas urbanos. Luego, en los años setenta fue retomado por el economista Loury.

Bevort afirma que la historia intelectual del capital social comienza en los sesenta en Estados Unidos y después, de manera independiente, en Europa en los años ochenta. Destaca a Bourdieu, Coleman y Putnam por haber problematizado la noción 
e introducir los principales temas que estructuraron el debate. Claudia Serrano (2001: 6), dice que las primeras aproximaciones al término están en Bourdieu, el cual parte de su concepto de habitus, refiriendo que las prácticas sociales son construcciones que pueden ser reguladas por los individuos para generar determinados códigos de preferencias y estímulos para la acción. De ahí que la acción repetida y socializada construye ámbitos de acción aceptados como válidos por medio de los cuales los individuos reconstruyen su espacio cultural y social.

\section{Síntesis de autores e ideas que han estructurado el capital social (elaboración propia)}

\begin{tabular}{|c|c|c|}
\hline Autor & ¿Qué es el capital social? & ¿Qué facilita el capital social? \\
\hline $\begin{array}{c}\text { Pierre } \\
\text { Bourdieu }\end{array}$ & $\begin{array}{l}\text { Recursos reales o potenciales de los } \\
\text { miembros de una red duradera de relaciones. }\end{array}$ & $\begin{array}{l}\text { Estimula la acción y la reconstrucción de } \\
\text { espacios culturales y sociales. }\end{array}$ \\
\hline $\begin{array}{c}\text { James } \\
\text { Coleman }\end{array}$ & $\begin{array}{l}\text { Relaciones socioculturales y activos que } \\
\text { poseen las estructuras de relaciones sociales. }\end{array}$ & Ciertas acciones comunes. \\
\hline $\begin{array}{l}\text { Robert } \\
\text { Putnam }\end{array}$ & $\begin{array}{l}\text { Redes de relaciones, normas y confianza que } \\
\text { tienen las organizaciones sociales. }\end{array}$ & La acción y la cooperación. \\
\hline $\begin{array}{l}\text { Jonathan } \\
\text { Fox }\end{array}$ & Redes y relaciones sociales. & La acción colectiva. \\
\hline $\begin{array}{c}\text { John } \\
\text { Durston }\end{array}$ & Normas, instituciones y organización. & $\begin{array}{l}\text { Confianza y cooperación entre personas, } \\
\text { comunidad y sociedad. }\end{array}$ \\
\hline $\begin{array}{l}\text { Stefan } \\
\text { Baas }\end{array}$ & $\begin{array}{l}\text { Cohesión social, expresión cultural y } \\
\text { comportamiento social. }\end{array}$ & $\begin{array}{l}\text { Sociedades más cohesionadas, más que una } \\
\text { suma de individuos. }\end{array}$ \\
\hline $\begin{array}{c}\text { Alejandro } \\
\text { Portes }\end{array}$ & $\begin{array}{l}\text { Disponibilidad de recursos en virtud de } \\
\text { pertenecer a redes o estructuras más amplias. }\end{array}$ & Satisfacción de necesidades. \\
\hline $\begin{array}{c}\text { David } \\
\text { Robinson }\end{array}$ & $\begin{array}{l}\text { Simpatía hacia otro que tienen las personas y } \\
\text { los grupos. }\end{array}$ & $\begin{array}{l}\text { Beneficios, ventajas y tratamiento } \\
\text { preferencial para otra persona o grupo. }\end{array}$ \\
\hline $\begin{array}{c}\text { Deepa } \\
\text { Narayan }\end{array}$ & $\begin{array}{l}\text { Normas, redes y relaciones que poseen las } \\
\text { instituciones formales e informales. }\end{array}$ & $\begin{array}{l}\text { Coordinación de acciones y el logro de } \\
\text { metas. }\end{array}$ \\
\hline $\begin{array}{c}\text { Francis } \\
\text { Fukuyama }\end{array}$ & Normas y valores compartidos. & $\begin{array}{l}\text { Cooperación social, defensa de intereses y } \\
\text { apoyo a las necesidades colectivas. }\end{array}$ \\
\hline $\begin{array}{c}\text { Douglass } \\
\text { North }\end{array}$ & Instituciones, normas y valores. & Confianza entre actores. \\
\hline
\end{tabular}

De lo hasta aquí señalado, se observa que el desarrollo teórico del concepto de capital social, por una parte es muy difuso y por otra presenta ambigüedades y contradicciones. Es así que se ha definido por sus funciones, o sea, para qué sirve, o por sus condicionantes, es decir, qué se requiere para que se desarrolle. Más adelante adoptamos un criterio operacional.

Sobre los beneficios de este capital, Serrano (2001: 7) los organiza de la forma siguiente: 


\begin{tabular}{|c|c|c|c|}
\hline $\begin{array}{c}\text { Activos o } \\
\text { beneficios }\end{array}$ & Individuales & Comunitarios & Societales \\
\hline $\begin{array}{l}\text { Bienestar } \\
\text { Beneficios } \\
\text { económicos y } \\
\text { materiales }\end{array}$ & $\begin{array}{l}\text { Acceso a información } \\
\text { laboral y a activos } \\
\text { económicos (vivienda, etc.). } \\
\text { Préstamos o sistemas } \\
\text { informales de crédito. } \\
\text { Intercambio de bienes y } \\
\text { enseres, acceso a iniciativas } \\
\text { productivas colectivas. }\end{array}$ & $\begin{array}{l}\text { Más desarrollo por el impulso } \\
\text { de emprendimientos colectivos. } \\
\text { Desarrollo de proyectos } \\
\text { comunitarios. } \\
\text { Mayor sustentabilidad de los } \\
\text { proyectos. } \\
\text { Mayor atracción de recursos } \\
\text { económicos y materiales. }\end{array}$ & $\begin{array}{l}\text { Incremento de los } \\
\text { intercambios } \\
\text { emprendimientos. } \\
\text { Contribución al desarrollo } \\
\text { económico. } \\
\begin{array}{l}\text { Generación de } \\
\text { productivos. }\end{array}\end{array}$ \\
\hline $\begin{array}{ll}\text { Integración } \\
\text { social } \\
\text { Beneficios } \\
\text { sociales y } \\
\text { culturales }\end{array}$ & $\begin{array}{l}\text { Reconocimiento y } \\
\text { aceptación social. } \\
\text { Desarrollo personal. } \\
\text { Ampliación del mundo de } \\
\text { referencia. } \\
\text { Conocimiento, información. } \\
\text { Sentimientos de utilidad y } \\
\text { valoración personal. } \\
\text { Destrezas y aptitudes. }\end{array}$ & $\begin{array}{l}\text { Fortalecimiento de la vida } \\
\text { social y comunitaria. } \\
\text { Acceso a servicios colectivos. } \\
\text { Mayor cohesión grupal. } \\
\text { Fortalecimiento de la identidad } \\
\text { comunitaria. }\end{array}$ & $\begin{array}{l}\text { Mejoramiento de la calidad } \\
\text { de los vínculos sociales. } \\
\text { Estímulo a la creatividad y } \\
\text { emprendimientos sociales. } \\
\text { Protección frente a riesgos } \\
\text { de fractura social. } \\
\text { Manifestación } \\
\text { de sentimientos } \\
\text { de respeto y solidaridad. }\end{array}$ \\
\hline $\begin{array}{ll}\text { Poder } & \text { e } \\
\text { influencia } & \\
\text { social } & \\
\text { Beneficios } & \\
\text { políticos } & \text { y } \\
\text { cívicos } & \end{array}$ & $\begin{array}{l}\text { Oportunidades para incidir. } \\
\text { Ejercicio del derecho a } \\
\text { petición y reclamo. } \\
\text { Derecho y ejercicio de voz } \\
\text { pública. } \\
\text { Disposición a participar en } \\
\text { iniciativas de interés } \\
\text { público. }\end{array}$ & $\begin{array}{l}\text { Capacidad de coordinación con } \\
\text { diferentes agentes. } \\
\text { Diálogo, negociación y } \\
\text { generación de acuerdos. } \\
\text { Más interacción con el aparato } \\
\text { público y con otros agentes. } \\
\text { Mejoramiento de la capacidad } \\
\text { de propuesta e intervención. }\end{array}$ & $\begin{array}{l}\text { Impulsa las virtudes cívicas. } \\
\text { Fortalece la ciudadanía. } \\
\text { Mejor relación ciudadanía - } \\
\text { aparato público. } \\
\text { Más control ciudadano } \\
\text { sobre la acción estatal. } \\
\text { Mejor coordinación } \\
\text { público-privado. }\end{array}$ \\
\hline
\end{tabular}

La centralidad del beneficio del capital social que asumimos en este artículo, es que una comunidad caracterizada por la ausencia o un bajo nivel de capital social le será mucho más difícil articular sus demandas. Este capital es, entre otras cosas, un recurso esencial tanto para superar problemas de acción colectiva como para facilitar que los individuos cooperen entre sí (Herreros Vázquez, 2005: 13). Si asumimos que este capital está al alcance de todos y que puede ser provechoso, también puede decirse que entre los distintos capitales (natural, económico, humano y social), el capital social es el más ignorado; de ahí su desconocimiento y poca utilidad como activo y factor de logro.

\section{LAS INVESTIGACIONES Y MEDICIONES DE CAPITAL SOCIAL}

Sobre este particular hay una opinión bastante difundida en el sentido de que este capital es un intangible y, por ello, resulta difícil de medir (Serrano, 2001: 1-2), no obstante no es imposible valorarlo. En este orden, la mayoría de investigadores y cientistas 
sociales han adoptado una serie de indicadores que facilitan el reconocimiento del mismo.

Desde la antropología, sociología, psicología social y las ciencias políticas, diversos autores han realizado esfuerzos cualitativos, cuantitativos y cuanticualitativos para valorar y/o medir parámetros como las relaciones interpersonales, vida asociativa y participación, trabajo en redes, información, cooperación, acción colectiva, liderazgo, confianza, cohesión, control social, gobernabilidad, entre otros, creando para tal efecto diferentes escalas de medición o criterios para la valoración. Figueroa Huencho (pp. 56, 80-91), en su tesis doctoral sobre capital social, refiere que las investigaciones fundacionales de Bourdieu (1980-1986) y Coleman (1987-1988-1990), en el área educativa y de Putnam (1993-1994), en el área de las ciencias políticas, han sido la principal fuente inspiradora de gran parte de las teorías que se han formulado, al igual que de los estudios realizados en diversas partes del mundo sobre el tema. Trabajos posteriores de cierta data pero referenciales son los estudios cualitativos de Narayan y Pritchett, en Tanzania (1997) y Durston y Duhart, en Chile (2003); los cuantitativos de Putnam, en Italia (1993) y Knack y Keefer, en 29 países de Europa, América y Asia (1997); los cuanticualitativos de Onyx y Bullen, en Australia (1998), Krishna y Uphoff, en India (1999), Putnam, en Estados Unidos (2000) y Consejero y Subirats, en España (2000).

En otra línea más reciente están las mediciones realizadas desde la economía. Aquí se ubican Montesino, Serrano, Fernández y Pérez (2005: 43-51), quienes consideran que el capital social tiene un valor productivo y proponen una metodología similar a la empleada en la medición de los activos financieros, físicos o humanos desarrollando tanto elementos teóricos como empíricos. El interés radica en los efectos del crecimiento, la eficiencia y productividad, con lo cual sugieren fórmulas econométricas para medir las implicaciones de causa efecto entre el capital social y el capital económico. Para esto cuantifican factores como la inversión, costos, tasas, tiempo, ganancias, valor agregado, entre otros aspectos.

\section{VISTAZO GENERAL AL REPARTO SAN JERÓNIMO}

Éste se localiza en el km 93 y 1/2 de la carretera hacia Chinandega, a unos de $3 \mathrm{~km}$ del centro de la ciudad. El barrio tiene cua- 
tro calles, una avenida, 209 casas y unos 1.200 habitantes. Las primeras familias se asentaron en el lugar a finales de los años 50 , sin embargo el reparto tomó forma a mediados de los 70 . Un elemento a destacar es que en el lugar hay muchos vínculos familiares entre sus habitantes.

Los servicios públicos con los que cuenta el reparto son: Electricidad domiciliar, alumbrado público (en una parte del barrio), agua potable, cancha deportiva, transporte público (desde 1975), alcantarillado sanitario (desde 2009), recolección de desechos sólidos (una vez por semana), escuela primaria (deteriorada) y calles de tierra. El barrio es de mucho riesgo ambiental. En el verano, dado la proximidad con áreas de cultivo y la poca forestación, las polvaredas producidas por la preparación de tierras para la siembra, impactan a los pobladores haciéndolos vulnerables a enfermedades respiratorias. En el invierno, dado el desnivel del terreno, se inundan algunas calles y el agua se introduce en varias casas. Esto es lo que marca a San Jerónimo como un reparto con poco progreso social.

Entrevistas preliminares evidenciaron dos tipos de hallazgos. De un lado se detectaron problemas de liderazgo, participación y gestión en dos organizaciones, el Concejo del Poder Ciudadano (CPC) y el Movimiento Comunal Nicaragüense (MCN). De otra parte se evidenciaron fuertes lazos de solidaridad y cooperación vecinal expresados en un grupo de jóvenes que proporciona seguridad ciudadana y una cooperativa que ayuda con parte de los gastos funerarios en caso de muerte de sus afiliados o de los beneficiarios de éstos.

\section{EL ENFOQUE ANALÍTICO SEGUIDO}

De Serrano (2001: 1-3), se pueden extraer ciertos elementos paradigmáticos: 1. Este capital posibilita desarrollo a los pobres en determinadas formas de sociabilidad; 2. Puede ser un mecanismo compensatorio que no cuestiona estructuras de desigual$\mathrm{dad}^{3}$; 3. Es un medio que mejora el acceso a recursos, favorece virtudes cívicas y estimula el interés por los asuntos públicos ${ }^{4}$.

${ }^{3}$ El léxico "bonachón" de este capital lleva a ignorar conflictos estructurales de poder, clase, etnia y género. Puede ser un reduccionismo presentado con leguaje no amenazante. (Serrano:3, refiere a Mohan y Stokke).

${ }^{4}$ Harris y De Renzio: Este capital no siempre es positivo, puesto que redes como las mafias son perniciosas para la sociedad (Alberdi y Pérez 2006). Olson: 
Ahora bien, el recorrido conceptual presentado al inicio puede resumirse y encuadrarse dentro de ciertas perspectivas. A decir de Arboleda Álvarez, Ghiso Cotos y Quiroz Lizarazo (2008: 7778), la vertiente teórica estructural representada por Bourdieu y Coleman definen el capital social relacionándolo con un conjunto de recursos disponibles para el individuo derivados de su participación en redes sociales. Desde esta perspectiva este capital tiene una referencia material sustentada por una red de relaciones interpersonales estables y duraderas que son las que permiten el acceso a recursos. Desde la perspectiva cultural, el capital social se concibe subjetivamente y está compuesto por valores y actitudes que condicionan las relaciones de unos con otros. En este sentido, para Fukuyama las leyes y la institucionalidad no son constitutivas de este capital sino un derivado de contenidos éticos y morales. En esta misma línea vale agregar a Kliksberg, para quien el capital social y la cultura son agentes activos del desarrollo económico y social y constituyen una propuesta viable que produce resultados efectivos.

Siguiendo a Álvarez, Ghiso y Quiroz, ambas perspectivas son complementarias, de un lado están las relaciones sociales y el orden social estructural y de otro los elementos culturales (las tradiciones, valores éticos y la moral compartida). Aquí es donde según estos autores surge el enfoque integracionista en el que se ubica Putnam, para quien las redes sociales son importantes y poseen valor, ante todo, para quienes se hallan en ellas, pero también estima que es en la cultura donde se encuentran los referentes para la sociabilidad.

Entre los tipos de capital social que existen, el caso que nos ocupó fue el comunitario ${ }^{5}$ y dado que elementos como las normas, la confianza, cooperación y cohesión social se usan indistintamente para decir lo que es o lo que facilita este capital, adop-

Lazos grupales fuertes (familiares, religiosos, étnicos, etc.), con intereses estrechos, pueden ser un obstáculo al desarrollo. Bentolila: Refiere como ejemplo de capital social negativo la alternativa que tienen quienes suelen buscar trabajo a través de amigos o familiares y tienen menos cualificaciones formales y menor nivel de estudios, con lo cual es natural que suplan con "capital social" sus carencias de capital humano. (Sánchez y Pena, 2005: 144).

${ }^{5}$ Para Durston, además del comunitario, otros tipos de capital social son: Individual, grupal, puente, escalera y societal (Márquez Zárate, 2009: 9-11). Woolcock (1999), distingue tres tipos de este capital: Bridging, bonding y linking. Putnam (2000), plantea los tipos siguientes: Vertical vs. horizontal, vínculos fuertes vs. débiles, bridging vs. bonding. Woolcock y Putnam son referidos por Portela y Neira (2002: 10). 
tamos una definición operacional que por razones didácticas se inscribe en la perspectiva integracionista.

El capital en estudio lo definimos como el conjunto de recursos que, fundamentados en valores y principios comunes, existen en las estructuras comunales y se manifiestan con relaciones de confianza, cooperación y reciprocidad, así como con normas, organizaciones, instituciones y redes que facilitan la acción colectiva para el logro de ciertas metas de desarrollo comunitario. Nuestro enfoque analítico sigue la postura crítica que considera al capital social como: a) Un activo más entre varios (Durston, 2000: 36); b) Un instrumento que, como afirma Bourdieu, permite mejorar los rendimientos de otras formas de capital (Sánchez y Pena, 2005: 139); c) Un enfoque que no sustituye la intervención estatal en la atención y solución de la problemática social (Navarro, 2003: 29, 30 y 35).

\section{SÍNTESIS DESCRIPTIVA DEL TIPO DE ESTUDIO REALIZADO}

La justificación del estudio se centra en dotar a la comunidad y a los actores externos de un diagnóstico sobre el tema al cual se podría recurrir para reconsiderar estrategias de intervención. Los objetivos fueron, el general, conocer el nivel de capital social comunitario y los específicos: a) Identificar indicadores de este capital; b) Analizar los factores que lo limitan; c) Valorar las posibilidades de mejora del mismo. Para esto adoptamos el criterio de que medir el capital social hace más entendible el concepto y posibilita su utilización (Velazco, 2009).

Por estimar más apropiadas al tipo de estudio, las dimensiones del capital social analizadas fueron la estructural y cognitiva (Uphoff \& Wijayaratna, 2000: 2-4) , es decir el tejido social formal

${ }^{6}$ Martínez, Sáenz y Ruiz (2006: 2-4), refieren a Nahapiety y Ghoshal para considerar tres dimensiones: 1. Estructural, relacionada con la participación, redes, acceso a información, recursos, etc.; 2. Relacional, contempla la generación de confianza, normas y convenciones sociales que rigen las obligaciones y expectativas mutuas; 3. Cognitiva, refiere un lenguaje común para acceder, comprender, asimilar y utilizar la información y los recursos de que dispone la otra parte. Atria (2003: 3-4) y Gutiérrez (2008: 7), establecen dos dimensiones principales: 1. Capacidad de movilización de determinados recursos, vinculada al liderazgo y empoderamiento, horizontalidad y verticalidad, es decir, con las relaciones en los grupos (bonding) y entre grupos similares (linking); 2. Disponibilidad de redes de relaciones sociales, referida a la capacidad efectiva de movilizar los recursos asociativos de un grupo (redes de relaciones externas "bridging"). 
e informal y los factores subjetivos que regulan las relaciones sociales. Las dimensiones se desarrollaron en componentes, éstos en indicadores y luego se adoptaron índices operacionales (Muy bueno/Muy alto/Muchísimo; Bueno/Alto/Mucho; Regular/Medio; Malo/Bajo/Poco; Muy malo/Muy Bajo/Muy poco).

\section{Matriz de Dimensiones, Componentes e Indicadores}

\begin{tabular}{|c|c|c|}
\hline Dimensión & Componentes & Indicadores $^{1}$ \\
\hline \multirow[t]{34}{*}{ Estructural } & \multirow{8}{*}{$\begin{array}{l}\text { Relaciones } \\
\text { interpersonales }\end{array}$} & Calidad de las relaciones vecinales \\
\hline & & Número de amigos cercanos en el vecindario \\
\hline & & Número de amigos cercanos fuera del vecindario \\
\hline & & Frecuencia de la sociabilidad con los vecinos \\
\hline & & Frecuencia de la sociabilidad con los amigos del vecindario \\
\hline & & Frecuencia de la sociabilidad con los amigos fuera del vecindario \\
\hline & & Tolerancia a la diversidad \\
\hline & & Tolerancia hacia extraños \\
\hline & \multirow{5}{*}{$\begin{array}{l}\text { Vida asociativa } \\
\text { y participación }\end{array}$} & Pertenencia y participación en grupos y organizaciones del reparto \\
\hline & & Aportes al trabajo comunitario \\
\hline & & Espontaneidad u obligatoriedad de la participación comunitaria \\
\hline & & Impedimentos de la participación en los asuntos comunitarios \\
\hline & & Toma de decisiones a lo interno de la organización comunitaria \\
\hline & \multirow{4}{*}{$\begin{array}{l}\text { Relaciones con } \\
\text { organizaciones } \\
\text { internas, } \\
\text { externas y redes }\end{array}$} & Participación de los grupos en redes internas \\
\hline & & Participación de los grupos y organizaciones en redes externas \\
\hline & & Relaciones interpersonales con funcionarios de organizaciones externas \\
\hline & & Articulación con organizaciones e instituciones \\
\hline & \multirow{8}{*}{$\begin{array}{l}\text { Información y } \\
\text { comunicación } \\
\text { sobre los } \\
\text { asuntos } \\
\text { comunitarios }\end{array}$} & Información dada por los amigos del vecindario \\
\hline & & Información dada por los vecinos \\
\hline & & Información dada por el liderazgo de las organizaciones comunitarias \\
\hline & & Información dada por funcionarios de organizaciones externas \\
\hline & & Diálogo, negociación y acuerdos entre vecinos y organización comunitaria \\
\hline & & Cumplimiento de normas y acuerdos entre actores internos del reparto \\
\hline & & Diálogo, negociación y acuerdos entre la comunidad y los agentes externos \\
\hline & & Cumplimiento de normas y acuerdos entre actores internos y externos \\
\hline & \multirow[t]{2}{*}{ Cooperación } & A lo interno (familias, amistades del reparto, vecinos, organizaciones) \\
\hline & & A lo externo (amistades fuera del reparto, organizaciones, instituciones) \\
\hline & \multirow{3}{*}{$\begin{array}{l}\text { Acción } \\
\text { colectiva }\end{array}$} & Elaboración de propuestas internas de la organización comunitaria \\
\hline & & Gestión y grado de éxito de las peticiones de la comunidad \\
\hline & & Ejecución de acciones para atender problemas del reparto \\
\hline & \multirow[t]{4}{*}{ Liderazgo } & Selección del liderazgo comunitario \\
\hline & & Funcionamiento del liderazgo a lo interno de la organización \\
\hline & & Respuesta a los problemas del reparto \\
\hline & & Grado de satisfacción con el liderazgo comunitario \\
\hline \multirow[t]{12}{*}{ Cognitiva } & \multirow[t]{6}{*}{ Cohesión social } & Porcentaje de personas del barrio fuera del país \\
\hline & & Unidad, sentido de pertenencia e identidad de pobladores hacia el reparto \\
\hline & & Nivel de problemas causados por asuntos religiosos \\
\hline & & Nivel de problemas por asuntos políticos \\
\hline & & Nivel de problemas entre vecinos nuevos y antiguos \\
\hline & & Nivel de problemas entre jóvenes y mayores \\
\hline & \multirow[t]{2}{*}{ Confianza } & Interna (en dueños de negocios, maestros, vecinos, organizaciones) \\
\hline & & En los agentes externos (funcionarios, instituciones, cooperantes, etc.) \\
\hline & \multirow[t]{4}{*}{ Control social } & Nivel de transparencia de las organizaciones comunitarias \\
\hline & & Conflictividad a lo interno de las organizaciones comunitarias \\
\hline & & Conflictividad en el reparto \\
\hline & & Seguridad del vecindario \\
\hline
\end{tabular}


Aparte de retomar los planteamientos de Uphoff y Wijayaratna, la matriz anterior refleja las variables del capital social propuestas por Atria (2003: 3-4), referidas a la participación en redes, reciprocidad, confianza, normas sociales y proactividad, al igual que lo sugerido por el Banco Mundial, (Gutiérrez, 2008: 7), que agrega otras variables como la solidaridad, acción colectiva, cooperación, cohesión social e inclusión, información y comunicación. Para el diseño de los instrumentos de recolección de datos se retomó y adaptó la encuesta sobre capital social del Banco Mundial.

El estudio que realizamos fue de tipo exploratorio, cuanticualitativo, transversal y prospectivo (Piura, 2006: 73-85). Atendiendo a los objetivos y siguiendo criterios de inclusión y exclusión se aplicaron encuestas a jefes de familias y entrevistas semiestructuradas a representantes de las organizaciones del reparto y a uno de los actores externos que intervienen en el mismo (a la responsable de la Dirección de Relaciones con la Comunidad de la Alcaldía de León). En correspondencia con lo anterior, la muestra de la investigación se definió sobre la base de algunos componentes típicos o característicos, aunque no estrictamente representativos (Quivy \& Campenhoudt, 2000: 154).

El nivel de capital social del reparto se obtuvo de la ponderación de resultados y de la triangulación de instrumentos. Esto fue posible dado que, sin incluir los datos generales de los encuestados y entrevistados, la mayoría de las preguntas del estudio, el $80 \%$ de las encuestas y el $42 \%$ de las entrevistas, fueron diseñadas a partir de una escala de medición operacional de uno (1) a cinco (5), donde 1 fue igual al peor valor y 5 al mejor valor. Así mismo, para poder realizar la ponderación de las respuestas cualitativas de las preguntas abiertas (el restante $58 \%$ de las preguntas de las entrevistas), fueron clasificadas conforme a una tabla de equivalencias cuantitativas. De acuerdo con la escala de medición (de 1 a 5), se aplicó un tipo de nivel de capital social operacional que siguió la valoración siguiente: $1=$ Muy escaso; $2=$ Escaso; 3= Intermedio, 4= En desarrollo; 5= Desarrollado ${ }^{7}$.

${ }^{7}$ Autores como Raúl Atria (2003: 4-5), en atención a la capacidad de movilización de recursos asociativos, considera tres niveles de desarrollo del capital social: 1. Capital social restringido: En el cual predominan las redes sociales internas (relaciones hacia dentro del grupo) y un liderazgo hacia dentro del grupo (liderazgo en el grupo). 2. Capital social en desarrollo: Este se puede presentar 


\section{LAS EVIDENCIAS POSITIVAS DEL USO INFORMAL DEL CAPITAL SOCIAL}

Entre los elementos que se destacan en el estudio están el clima de confianza social vecinal, la unidad, el sentido de pertenencia e identidad hacia el reparto y dos importantes experiencias precursoras de capital social.

Sobre el primer aspecto, todos los encuestados y entrevistados valoraron muy bien las relaciones interpersonales y vecinales entre los pobladores, lo mismo que la tolerancia hacia los extraños y a la diversidad y, en general, se subraya que la gente del reparto es muy amable. Esta manifestación de personalidad positiva, que sin duda tienen los vecinos de San Jerónimo, puede explicarse también por los múltiples vínculos familiares que existen entre los pobladores desde la fundación misma del reparto.

Quizá congruente con esto, hay un bajísimo nivel de conflictividad entre los vecinos y si se presentan algunos problemas no son relevantes y suelen además solucionarse rápido. A lo anterior hay que sumarle el alto grado de seguridad ciudadana del barrio más el excelente indicador confianza que existe hacia los dueños de negocios de la comunidad y en alguna medida también, porque no deja de ser positiva o regular, la confianza hacia los maestros y hacia o entre los vecinos mismos.

Estos factores indican que en el lugar existe buena cohesión y control social, lo cual constituye una precondición favorable o relación de causalidad para impulsar el desarrollo del este capital. Para Lorenzelli (2003: 5-8), la existencia de una cultura de confianza entre las personas que comparten un espacio físico (escuela, oficina, barrio, comunidad, etc.), es base fundamental para posibilitar la generación y acumulación de capital social.

Otro de los elementos muy bien valorados por los sujetos de estudio fueron la unidad, el sentido de pertenencia e identidad de los pobladores hacia el reparto, los cuales presentan un saldo

con dos variantes. En la primera hay predominio de redes sociales internas (relaciones hacia dentro del grupo) y un liderazgo hacia fuera del grupo (liderazgo para el grupo). En la segunda se manifiesta un predominio de redes sociales externas (relaciones hacia fuera del grupo) y un liderazgo hacia dentro del grupo (liderazgo en el grupo). 3. Capital social ampliado: Hay predominio de redes sociales externas (relaciones hacia fuera del grupo) y un liderazgo hacia fuera del grupo (liderazgo para el grupo). 
de positividad de +58 (79\% positivo, $21 \%$ negativo). Lo llamativo es que esta unidad e identificación se mantiene muy a pesar del histórico aislamiento estructural al que el reparto ha estado sometido. Como señalamos al inicio, esta comunidad es de las más antiguas de la periferia norte de la ciudad de León con uno de los más bajos niveles de progreso social en relación a otros barrios que surgieron con posterioridad al mismo.

El estudio reveló que el $73 \%$ de los encuestados tienen más de 16 años de vivir en el lugar y el 53\% tiene más de 21 años de residencia. Si bien no profundizamos más sobre este particular, creemos que los indicadores positivos de buena vecindad, familiaridad y seguridad ciudadana son parte de la explicación del arraigo de los vecinos al barrio, pero seguramente son también el reflejo, de un lado, de la característica conservadora de los pobladores y, de otro, de una actitud conformista frente a las carencias del reparto. Como decíamos, el hecho es que a pesar del déficit histórico de infraestructura urbana del barrio aún prevalece el sentido de pertenencia e identificación hacia el mismo, sin embargo éste no se ha sabido aprovechar como para disponerlo en función del desarrollo comunitario. En este particular Mary Luz Alzate Zuluaga (2008: 294), en referencia a Melucci y Gamson, resalta que la identidad es un factor relevante para la realización de la acción colectiva. Si esto es así, entonces el sentido de pertenencia e identificación de los pobladores de San Jerónimo hacia su reparto es otro elemento positivo de capital social subyacente.

Aparte de que en el lugar se encontraron evidencias de una muy buena cooperación vecinal, por ejemplo cuando en el invierno se presentan inundaciones que afectan a una parte de los vecinos y se hacen manifiestas las muestras de solidaridad y ayuda, los hallazgos más significativos del estudio son la eficaz brigada juvenil de seguridad ciudadana y el exitoso desempeño de la Cooperativa de Servicios Funerarios.

La primera de las experiencias es producto de la iniciativa de una parte de los pobladores por dar mayor seguridad al reparto. Con este propósito se encargó esta tarea a un grupo de jóvenes de la comunidad a los cuales, para facilitar el cumplimiento de su cometido, se les facilitó ciertos equipos de defensa aprovechando que en el barrio habita un importante exjefe de policía de la ciudad. Los hechos delictivos que se daban provenían de sujetos 
externos a la comunidad y cuando el grupo juvenil organizado lograba capturar a los perpetradores los ponía a la orden de las autoridades competentes, dándose en este caso un accionar eficaz con la policía. La intervención de este grupo de jóvenes ha prevenido y disuadido la delincuencia que antes afectaba al reparto, haciendo que los habitantes de San Jerónimo tengan una muy buena percepción de seguridad ciudadana en su comunidad.

La segunda de las experiencias exitosas es la Cooperativa de Servicios Funerarios conocida también como "La Fraterna". Esta iniciativa se inició el 6 de julio de 2003 y a la fecha del estudio contaba con más de cien socios y unos seiscientos beneficiarios (aproximadamente la mitad de los hogares y pobladores del reparto). El beneficio por pertenecer a esta cooperativa consiste que en caso de fallecimiento de los afiliados o beneficiarios, la familia del difunto recibe una suma de dinero estimada en ese entonces en unos $\$ 400.00$, más una ofrenda floral y el préstamo de sillas para el velatorio. A esta cooperativa pueden pertenecer sólo los habitantes del barrio que paguen a la entrada de la misma la suma de $\$ 9.00$, aproximadamente, y luego tienen que dar como cuota mensual la cantidad de $\$ 0.90$. Los fondos de esta cuota mensual se administran en caja chica y el dinero se destina para el funcionamiento de la cooperativa. Cuando se produce un fallecimiento, los socios tienen que dar aproximadamente la cantidad de $\$ 4.00$ para reponer el capital principal que se entrega a la familia beneficiaria. Un elemento notable de esta cooperativa es que, después de 7 años, no poseía personalidad jurídica. No obstante, a título personal de sus directivos, esta organización tiene cuentas en dos bancos y crédito en dos funerarias de la ciudad y a la fecha del estudio había beneficiado a 22 familias. Sus miembros han depositado una enorme confianza en la organización y su liderazgo, razón por la cual participan activa y disciplinadamente. La organización funciona desde su fundación de forma muy eficiente en relación al resto de organizaciones que existen en la comunidad.

Esta organización cooperativa, única en su naturaleza a nivel comunitario por lo menos en el municipio de León, es la principal y más interesante evidencia de un fuerte lazo de solidaridad y cooperación vecinal. Esta preocupación y ocupación de una parte importante de la comunidad para enfrentar un hecho social significativo como la muerte, es una variable singular en relación 
a la disponibilidad de los vecinos para hacerle frente a otros desafíos que pueda tener el barrio. Por otra parte, hay que agregar que el beneficio que reciben los miembros de esta organización, sumado al hecho que solamente los habitantes del reparto son los únicos que pueden pertenecer a esta cooperativa, les proporciona a sus pobladores cierta noción de destino y un fuerte sentido de pertenencia. La cooperativa liga en cierta forma a sus integrantes a la comunidad, por cuanto, si cambian su residencia fuera del reparto pierden la calidad y los beneficios de socio.

Al respecto, Aguirre y Pinto (2006: 82), en referencia a Durston, señalan que se requiere que existan ciertos "precursores", que son experiencias sociales y culturales que están en la base, para que surja la realidad del capital social. Estas experiencias precursoras son entre otras la memoria social e histórica; la identidad y la etnicidad; la religiosidad compartida; la vecindad y la cercanía geográfica; la amistad y el compañerismo; las relaciones de parentesco; los principios y las prácticas de reciprocidad. Cada una de estas experiencias propicia el surgimiento de la confianza y la cooperación como elementos articuladores de capital social.

Volviendo a Lorenzelli (2003: 8), desde la perspectiva de la construcción comunitaria, lo que está implícito en estas dos experiencias precursoras de capital social es la relación de causalidad que ya referíamos, es decir, que el clima de confianza social entre los vecinos, las múltiples relaciones familiares y el liderazgo de ciertas personas del reparto favoreció la aparición de esas formas de grupo o asociaciones en la comunidad. Por otra parte, siguiendo siempre a Lorenzelli (p. 5), estas exitosas experiencias organizativas representan dos tipos de capital social. El grupo juvenil de seguridad ciudadana, al beneficiar a todo el reparto, es una expresión de capital social de tipo comunitario, en cambio, la Cooperativa de Servicios Funerarios es una muestra de capital social de tipo grupal porque beneficia a las personas involucradas en esa estructura u organización social y por lo tanto genera rendimientos individuales o grupales, que bien pueden ser comunales.

\section{EVIDENCIAS NEGATIVAS DE CAPITAL SOCIAL}

Los elementos más visibles revelados por el estudio son el conformismo de los pobladores, la estructura tradicional formal y 
la desconfianza de los vecinos en la organización comunitaria y en las instituciones externas.

Como señalamos antes, todos los sujetos de investigación afirmaron que existe un alto grado de unidad, sentido de pertenencia e identidad hacia el reparto (saldo de positividad de +58 : $79 \%$ positivo, $21 \%$ negativo), pero paradójicamente este indicador no se corresponde con la frecuencia y espontaneidad de la participación ciudadana para hacerle frente a los problemas del barrio. A decir de los pobladores encuestados la frecuencia y la espontaneidad de la participación tienen, respectivamente, un saldo de positividad de +16 (58\% positivo, $42 \%$ negativo) y +12 (56\% positivo, $44 \%$ negativo). Si bien el saldo de las tres variables es positivo $(+58,+16$ y +12$)$, también es cierto que es grande la brecha entre el sentido de pertenencia y la frecuencia de la participación $(58-16=42)$ y entre aquel y la espontaneidad de la participación $(58-12=46)$. Así mismo, aunque un poco más de la mitad de los encuestados dijeron que participan en las actividades comunitarias, el 88\% expresó tener obstáculos para participar; la mayoría refirió los asuntos laborales y el desinterés como los principales impedimentos. Contrario a esto, los líderes y la funcionaria entrevistada coincidieron en que la frecuencia de participación es baja e inducida y que además hay mucho conformismo; "la gente espera que otros hagan algo por ella".

En cuanto al funcionamiento de las organizaciones comunitarias, se revela la presencia de estructuras tradicionales formales. Tanto el Consejo del Poder Ciudadano (CPC), como el Movimiento Comunal Nicaragüense (MCN), evidencian poca participación, escasa elaboración, gestión y ejecución de propuestas, accionar ineficaz en los proyectos de infraestructura, contacto con instituciones insuficiente y un liderazgo dependiente. La reciente aparición de los CPC, que son producto no de la necesidad comunitaria, sino del esquema de incidencia del partido Frente Sandinista de Liberación Nacional en el gobierno, provocó el desplazamiento de las estructuras y el liderazgo que ejercía el MCN. No obstante, estas organizaciones han tenido buen desempeño en el impulso de jornadas de salud comunitaria, deportes, atención de emergencias por lluvias, entre otros. Pero resulta que lo que más se echa en falta es la desatención de las viejas carencias de infraestructura urbana del reparto (calles de tierra, deterioro 
de la escuela, etc.), estos problemas son el principal parámetro de comparación para acusar falta de progreso respecto a otros repartos vecinos, con lo cual la gente de San Jerónimo no valora bien la gestión de las organizaciones comunitarias ni la intervención de los actores locales y nacionales.

Otra evidencia negativa de capital social es el poco cumplimiento de los acuerdos tanto a lo interno del reparto como los que se dan entre la comunidad y los agentes externos. Esto también tiene como consecuencia la desconfianza de los pobladores en la organización comunitaria y en los actores externos. La desconfianza promedio hacia la organización comunitaria y hacia los agentes externos es de $-34 \%$ (33\% positivo, $67 \%$ negativo).

Si para valorar el nivel de capital social utilizáramos la propuesta de Atria (2003: 4-5), todas las evidencias anteriores son características contrarias al capital social de tipo ampliado, el cual requiere predominio de redes sociales externas y un liderazgo comunitario con capacidad de gestión e incidencia en las instituciones de forma tal que beneficie a los pobladores. Desde este enfoque, lo que se observa en el reparto es un capital social restringido, es decir, con cierto predominio de redes sociales internas (relaciones hacia dentro del grupo) y un liderazgo hacia dentro del grupo (liderazgo en el grupo).

\section{EL DESUSO FORMAL DEL CAPITAL SOCIAL}

Vistos los resultados, en el reparto hay un enorme desconocimiento sobre lo que es el capital social. Sólo el $6 \%$ de los pobladores encuestados conoce algo del término. Los líderes entrevistados expresaron el mismo desconocimiento y agregaron que no han impulsado iniciativas sobre el tema, ni de parte de ellos ni de las instituciones que hasta ahora intervienen en el barrio. Relacionando este desconocimiento con la teoría del capital social, en Miranda y Monzó (2003: 12-13), encontramos que si se pretende utilizar el capital social como herramienta para superar la pobreza es necesario politizar el análisis de este capital y reconocer que sus efectos dependen del uso que pueda darse al mismo. Atendiendo al criterio seguido en este estudio, la pobreza o los problemas de infraestructura urbana del reparto no se superarán por el sólo conocimiento o utilización del capital social, pero sí podría ocurrir que si se pone en práctica esta categoría 
se mejoren la gestión comunitaria y se amplíen las posibilidades de acceso a ciertos a recursos que beneficien al reparto. Lo que está claro es que la referida politización no ha llegado al barrio, lo único que se experimenta, por decirlo en términos positivos, es un uso informal de este capital por razones de sentido común y necesidad funcional de la comunidad.

\section{ESTIMACIÓN DEL NIVEL DE CAPITAL SOCIAL EN SAN JERÓNIMO Y ACCIONES PARA MEJORARLO}

A pesar del desconocimiento formal del término, la ponderación de resultados reveló un nivel intermedio de capital social comunitario. Sin embargo, dada la calidad de las evidencias positivas encontradas existe un gran potencial para el desarrollo de este capital. Este paso dependerá en la medida que se produzca una extensión y conversión del capital social grupal (como el de los servicios funerarios) en capital social comunitario, es decir intentando, como dice Lorenzelli (2003: 9), que las prácticas de cooperación y las expectativas de reciprocidad se puedan acumular o replicar en otros ámbitos. Otra parte del problema parece radicar en que los vecinos no se autoreconocen como actores, para ellos, autogestionar los servicios funerarios no es ser actor, es parte de la vida cotidiana. De ahí que otro desafío subyacente es que las gentes se auto reconozcan plenamente como actores.

En cuanto a la mejora de este capital, es preciso impulsar un amplio proceso de capacitación, así como apoyar las experiencias precursoras que ya existen y procurar que todos los actores que intervienen utilicen el enfoque de capital social de forma integral y coordinada (Viteri Díaz, 2006: 23-24). Los sujetos de estudio sugirieron realizar actividades recreativas, culturales y deportivas para generar una mayor socialización y confianza como ambiente favorable para promover una mejor acción colectiva.

\section{REFLEXIONES SOBRE EL POR QUÉ DEL DESUSO FORMAL DEL CAPITAL SOCIAL}

Desde hace casi 100 años, cuando Hanifan precursoramente utilizara por primera vez el término de capital social y desde el inicio del desarrollo de este tema hace unos treinta años (Bevort, 
2007: 4), lo cierto es que ha transcurrido mucho tiempo y no se ha universalizado este concepto. Lo perceptible en San Jerónimo es que el término no está en la jerga de las instituciones ni de las organizaciones que ahí intervienen. Lo usual son categorías o enfoques como los de género, empoderamiento, equidad, sostenibilidad, ciudadanía, etc. Sin embargo, es entendible que el recorrido histórico de estos términos no sea el del capital social en el sentido de que los primeros han sido el centro de las reivindicaciones de los movimientos políticos y sociales que, entre otras cosas, siguen costando penas y sangre. Pero, sin pretender hacer comparaciones de conceptos que no son equiparables, lo que queremos es llamar la atención de que el capital social no se conoce.

En la actualidad, en muchos espacios, niveles y dimensiones sociales, existe un enorme desconocimiento formal acerca del contenido, importancia y utilidad de este término. Esta subsecuente escasa conciencia colectiva obviamente no ha permitido visibilizar ni interiorizar qué dimensiones, componentes e indicadores de este capital es necesario mejorar y/o potenciar, con lo cual estamos asistiendo al desuso o en el mejor de los casos al uso inconsciente o informal del capital social.

Ha pasado que las instituciones públicas y las organizaciones que tienen presencia en San Jerónimo, no han llevado expresamente esta categoría a los espacios vitales de las personas y colectivos con los que intervienen. Congruente con esto valdría entonces preguntarse varias cosas ¿Será que muchos agentes de intervención y cooperación desconocen el término? O si lo conocen ¿Por qué no ha calado el enfoque de capital social? ¿Creerán que se ha sobredimensionado la importancia y utilidad de éste y que en realidad no añade nada a lo que naturalmente ya hace la gente? ¿Existen otras categorías equivalentes más importantes o más prácticas que ésta? ¿Han ganado la batalla los enfoques que lo consideran como un intangible difícil de medir? ¿Pensarán que no hay que aplicar esta categoría por cuanto es un enfoque reduccionista que conduce a mediatizar conflictos estructurales de poder, clase, género o étnicos? O quizá se cree que el capital social debe surgir espontáneamente de las personas y colectividades para que pueda ser aprovechado o que la intervención que realizan las instituciones lleva implícito el capi- 
tal social y por tanto no necesitan darle un enfoque particular al trabajo que desarrollan. En otro caso, también cabe pensar que el término y su utilización puede llegar a ser transformador de la sociedad y, por tanto, quienes manejan el poder no lo van a impulsar. Estas preguntas sólo son algunas entre las que saltan sobre el por qué del desuso del capital social.

Es claro que muchos actores que hacen intervención social realizan un importante trabajo para facilitar que las personas y colectividades se apropien de sus problemas y de las soluciones. De ahí que, no es que estos actores no promuevan capital social, sí lo hacen y pueden seguirlo haciendo pero no formal ni conscientemente como para que los potenciales beneficiarios de su intervención se agencien de este capital en la forma que aquí lo abordamos; como activo que permite mejorar los rendimientos de otras formas de capital.

A decir de González de la Rocha (Arriagada, 2005: 65): "El desarrollo conceptual en torno a la noción de capital social ha ocurrido en paralelo a la discusión de la política social y la pobreza y han sido escasos los intentos por construir puentes entre ambos cuerpos de ideas, a pesar de la existencia de ejes en los que convergen".

Siempre en Arriagada (2005: 109 y 125), encontramos que Raczynski y Serrano sostienen que la política social que se ha llevado adelante en Chile, principalmente desde los años noventa, ha mostrado preocupación por dos componentes. Primero el fortalecimiento de políticas sectoriales que aseguran un nivel básico de servicios para la población: educación, salud, vivienda, seguridad social, trabajo y justicia. El segundo componente es el constituido por programas específicos dirigidos a situaciones de pobreza, precariedad, riesgo social y vulnerabilidad, en los que se concentran las experiencias que aluden al enfoque del capital social. Independientemente de la consistencia o no de lo dicho hasta aquí por estos autores, lo que refieren, como soporte de lo que queremos plasmar en este artículo, es que el término de capital social se utiliza de modo ambiguo equiparándolo a veces con sociedad civil, ciudadanía, redes sociales, asociatividad o a veces simplemente con el mejoramiento del acceso a los beneficios de los programas sociales. Al examinarse la capacidad del Estado de hacerse cargo de un enfoque de capital social, ambos 
autores consideran que: "De hecho, no se puede afirmar que en la práctica en los programas públicos se esté usando el marco analítico operativo propio del capital social".

Por otra parte, para los efectos de redacción de este artículo, examinamos las experiencias que internacionalmente se destacan en el contexto iberoamericano como precursoras y exitosas de capital social, entre éstas: el desarrollo local de Villa El Salvador, en Perú y las ferias de consumo familiar de Barquisimeto, en Venezuela ambas en Viteri Díaz (2006: 20-22); el presupuesto participativo de Porto Alegre, en Brasil por Zander Navarro, en Arriagada (2005: 171, 180-187, 190-191); el empoderamiento rural del proyecto anti pobreza PROZACHI, en Chiquimula, Guatemala (Durston, 1999: 12-21); y el cooperativismo de Mondragón, en el Alto Deba, País Vasco en Aitziber Mugarra Elorriaga (2005: $306,315-318)$. Pero ¿qué fue lo que encontramos? Exceptuando el caso guatemalteco, el resto de estas experiencias no son producto de una manifiesta intervención con enfoque de capital social, sino el resultado estructural y natural de un arraigado entramado de relaciones de confianza y cooperación vecinal, local u organizacional más o menos históricos. Esto ha provocado que las comunidades y organizaciones, las que tienen este potencial en la memoria histórica y/o en ciertas prácticas cotidianas, atiendan sus problemas mediante el impulso de una eficaz acción colectiva que ha impactado positivamente en la vida de las mismas. Guardando las distancias, lo que se observa es que la necesidad y el gran sentido común de ciertas organizaciones, grupos y comunidades, como el caso de la brigada de seguridad ciudadana y la Cooperativa de Servicios Funerarios de San Jerónimo, los ha hecho cuidar, ampliar y aprovechar las relaciones sociales, la confianza y la cooperación recíproca para adaptarse a su entorno y satisfacer ciertas necesidades.

Sucede también que mucho se desconocen las experiencias de capital social y en los sitios donde hay algunas evidencias positivas del mismo no son debidamente apoyadas como para que se desarrollen, como en efecto no se ha apoyado en San Jerónimo la obtención de la personalidad jurídica de la Cooperativa de Servicios Funerarios. Suele ocurrir que las gentes y los grupos saben que tienen cierto tipo de este capital y lo usan, unos más otros menos, pero no saben qué es ni cómo aprovecharlo mejor. 
Esto nos hace pensar que el brotar y desarrollo del capital social ha quedado casi a merced de la suerte o de la espontaneidad. Con excepción de organismos internacionales como Naciones Unidas, por medio de la Comisión Económica para América Latina y el Caribe (CEPAL), el Banco Mundial y el Banco Interamericano de Desarrollo (BID), aparte del enfoque más o menos reduccionista que puede prevalecer en el accionar estos actores, son los agentes que se destacan en Latinoamérica por impulsar iniciativas formales de capital social ${ }^{8}$. Aparte de esto, la socialización de esta categoría ha sido poca, aislada y a escala micro.

Lo evidente es que los gobiernos, nacionales o locales como en Nicaragua, no tienen incorporado este capital como enfoque o eje transversal en las políticas públicas ni tampoco muestran mayor interés en ocuparse del tema. Esto mismo ocurre con la sociedad civil y los agentes económicos. Aquí merece consideración lo dicho por Herreros Vázquez (2005: 15-17), el cual expone que hay dos enfoques para la creación de este recurso, el liberal que acentúa el papel "espontáneo" de la "sociedad civil" en auto organizarse y el socialdemócrata que enfatiza el papel del Estado.

El liberalismo considera que la mejor forma de favorecer la creación de capital social sostenible es dejar todo el protagonismo a la sociedad civil. Para este autor los planteamientos de Putnam son un buen ejemplo de esta perspectiva. Putnam reúne en sus trabajos una serie de experiencias estadounidenses acerca de cómo se pueden crear o recrear lo que denomina "comunidades cívicas" apoyadas por el capital privado y relegando a las instituciones públicas a un papel marginal; la función de estas últimas es apartarse y dejar hacer. El Estado es, en el mejor de los casos, un agente neutro en la creación de capital social y,

${ }^{8}$ La CEPAL realiza investigaciones, foros y publicaciones sobre el tema. El Banco Mundial ha realizado estudios de capital social en algunas partes del mundo y han confeccionado un cuestionario integrado para la medición de este capital, el cual ha sido incorporado en Guatemala como anexo en la encuestas de medición del nivel de vida. EI BID ha impulsado la denominada Iniciativa Interamericana de Capital Social, Ética y Desarrollo que, entre otras cosas, ha facilitado la inclusión del enfoque de capital social en la ejecución de proyectos de desarrollo, promueve en alguna medida la integración a los currículos educativos de la temática del capital social y la ética para el desarrollo y ha apoyado la conformación de una red de centros académicos de investigación y publicaciones contribuyendo de alguna manera al debate sobre el tema y su difusión. 
en el peor, un destructor consciente del mismo. En el enfoque socialdemócrata, Herreros recalca el papel del Estado, pero reconoce que éste puede erosionar el capital social como en el caso de las renovaciones urbanísticas que destruyen comunidades locales o el papel de los Estados comunistas en la destrucción de iglesias, asociaciones voluntarias y, en general, cualquier tipo de organización al margen del Estado y el partido en el poder. Siguiendo esta lógica, creemos que esto también sería aplicable a los sistemas autoritarios o totalitarios capitalistas alérgicos a la democracia política. Sin embargo, volviendo a Herreros, éste insiste en que el Estado puede jugar un importante papel en la creación de capital social indirecto (mejora del nivel educativo, mayor igualdad en la distribución de la renta, etc.) y directo (como garante de acuerdos y adoptando el enfoque de capital social en las políticas públicas). Para este autor estos dos enfoques no son necesariamente incompatibles, pero el rol del Estado es clave si se pretende institucionalizar la utilización de este recurso. Llevando el planteamiento de Herreros a la práctica, podemos decir que los partidos en el poder, por acción u omisión deliberada o no, bien pueden abrazar cualquiera de estos enfoques independientemente del corte ideológico con el que llegan al gobierno o del que dicen poseer o practicar.

Otro probable factor causal de la falta de universalización del capital social, en referencia a la formación y consecuencias del capital social en España, es el planteado por Mariano Torcal y José Ramón Montero (2000: 80; 86-88; 93; 101-102; 106-107). Estos autores confieren a la política un papel esencial en la formación del capital social. En España, hasta 1997, los porcentajes de afiliación y participación en partidos políticos, sindicatos y otras asociaciones voluntarias eran los más bajos de Europa. Sobre esto señalan que, si bien, desde la transición democrática española iniciada a mediados de los años 70, el número de asociaciones había crecido, no por eso se habían favorecido las actitudes de confianza interpersonal, la cual consideran básica para la formación del capital social. Parece ser que la supremacía de los intereses políticos partidarios dificultó la institucionalización de las asociaciones voluntarias. Así mismo, refieren que la confianza interpersonal se ha mantenido en niveles bajos en las distintas generaciones como consecuencia de los procesos 
de acumulación cultural que transmiten la imagen de experiencias políticas cristalizadas en el pasado y que paradójicamente se revitalizan a través de sentimientos hacia la política marcados por el cinismo, el desafecto y la alienación. En consecuencia los bajos niveles de confianza interpersonal son el resultado de la acumulación de experiencias, contactos y discursos políticos negativos que se han transmitido intergeneracionalmente.

Esto es lo que Sara Gordon (2006: 399-400), encuadra como parte del entorno institucional. En referencia a Knight, Gordon señala que "las instituciones son tan importantes como el compromiso cívico de los ciudadanos y si éstas estimulan el cumplimiento de las normas sociales, favorecerán la cooperación de los individuos". Esta misma autora reseña a Levi y Rothstein, para insistir en que "la confianza se crea desde arriba, de ahí que las instituciones políticas que son percibidas como justas y razonablemente eficientes, incrementan la probabilidad de que los ciudadanos cooperen".

De otro lado, autores como Putnam o Fukuyama, referidos por Enrique Gil Calvo (2006), señalan que las reservas de capital social comenzaron a decaer por Occidente a partir de la década de los 60 en la que habían alcanzado lo que parecen entender como su máximo histórico. Es lo que se ha llamado como el declive del capital social ${ }^{9}$; esto es una presunta tendencia regresiva en las relaciones de confianza mutua entre los ciudadanos y entre éstos y las autoridades. Pero autores como Vicenc Navarro y otros han criticado a Putnam señalando que el enfoque de capital social de éste es mediatizador del conflicto social ${ }^{10}$.

${ }^{9}$ Gil Calvo refiere que Fukuyama explica esta decaída por la erosión del tejido familiar causado por el declive de la autoridad paterna y el incremento de la participación laboral femenina. Putnam, tras repasar factores como el impacto corrosivo de la televisión, entre otros, polémicamente atribuye el declive a la socialización interiorizada por la generación que hizo la guerra de Vietnam, la cual a su decir fue mucho más desertora de sus compromisos cívicos en comparación con el elevado civismo de la que participó en la II Guerra Mundial. Así, la contracultura de los años 60 sería la iniciadora directa del declive del capital social.

${ }^{10}$ A nuestro criterio, es claro que Putnam no solo deslegitima el proceso de construcción social de la protesta contra la guerra de Vietnam, sino que, peor aún, no valora ese accionar masivo y efectivo de protesta como un indicador positivo de capital social de tipo societal, que incidió sustantivamente en una decisión política de Estado, como fue el retiro de las tropas estadounidenses de Vietnam. Este marcado sesgo ideologizado de Putnam nubla y desdice parte de sus propios planteamientos sobre lo que es y puede producir el capital social. 
Retomando a Gil Calvo, éste plantea que según qué indicadores utilicemos obtendremos tendencias progresivas o regresivas, con lo cual habrá que determinar muy concienzudamente la ponderación de las variables en cada caso. Gil relaciona cuatro factores de corrosión a través de los cuales parece manifestarse la declinación del capital social: El descrédito de la política, el impacto de la globalización, la quiebra de la reproducción familiar y el conflicto interétnico o multicultural.

Al respecto aclaramos que en esta investigación no relacionamos estos factores porque a decir verdad, como en el caso de los aspectos políticos, erróneamente pensamos que realizar preguntas de este tipo, sobre todo en una sociedad polarizada como la nuestra, podía causar cierto sesgo al estudio y, por tanto, no entraron en nuestro esquema original. Pero resulta que el avance del análisis y la reflexión realizada para la preparación de este artículo nos hacen ver que tanto la perspectiva política, por la relación con las dimensiones del poder, como la de globalización, por su relación con el neoliberalismo y el individualismo dominante, debieron haber tenido presencia en el estudio y ahora creemos que ineludiblemente hay que incluirlas en futuras investigaciones. Los otros dos aspectos, los familiares y étnicos, tampoco fueron incluidos, pero en este caso la razón fue que en las entrevistas

No obstante, volviendo a Gil Calvo, hay otro conjunto de datos empleados por Putnam de gran interés, por ejemplo el hecho de haber utilizado como paradigma las ligas de bolos \& mdas. En este caso señaló que éstas experimentaron una grave disminución de miembros, mientras que el número de "los que juegan solos a los bolos" se incrementó tremendamente. Es de recordar que entre los tipos de capital social Putnam distingue el capital vínculo y el capital puente (bonding vs. bridging). El vínculo se da cuando la persona socializa con otros semejantes de la misma edad, raza, religión, etc. Pero para crear sociedades pacíficas en un país multiétnico se necesita otra clase de vínculo; el que tiende puentes. Los puentes se tienden cuando se crean lazos con gente distinta, como los hinchas de otro equipo de fútbol. Putnam afirma que los que cuentan con ambos tipos de vínculo se fortalecen mutuamente, en consecuencia, el declive del capital enlace inevitablemente produce el declive en el capital puente, lo que desencadena tensiones étnicas y religiosas. (Ver en la referencia bibliográfica el declive del capital social de Robert Putnam).

La crítica de Navarro refiere que, entre otros aspectos, lo que está en el fondo del planteamiento de capital social de Putnam es hacer que los individuos incrementen su cantidad de capital a partir del uso de las redes, la confianza, etc., para convertirse en "capitalistas sociales", lo cual soslaya las relaciones de poder, de clase y etnia que configuran las políticas públicas y las desigualdades sociales provocadas por éstas. 
preliminares no se detectaron problemas de esta índole. Sin embargo, sin duda alguna las anotaciones de Torcal, Montero, Gil, Navarro y Gordon son un aporte a la discusión sobre las diferentes perspectivas de análisis de este capital, así como de las causas de la falta de generación del capital social de tipo societal que atendiendo a cada contexto debe tener un determinado impacto en la producción del capital social de tipo comunitario.

\section{A MANERA DE CIERRE}

Como se ha sugerido en estas líneas, sin obviar que hoy en día parte de la discusión sobre el capital social gira en derredor que se le considere como una perspectiva reduccionista o crítica de la problemática social, parece ser que lo que menos se discute es su utilidad práctica. De ser así, no debería representar mayor problema la difusión, apropiación y uso de éste como activo que tiende a mejorar la acción colectiva y los rendimientos de otras formas de capital. ¿Qué hay que hacer entonces? Idealmente, a nivel global, las instituciones internacionales que han protagonizado la discusión y las iniciativas sobre este tema deben impulsar su relanzamiento en todos los foros, de tal forma que se lleguen a concretar compromisos de parte de los Estados en la adopción como enfoque de las políticas públicas; que los agentes económicos vean al capital social no como un intangible, sino como un medio que incida positivamente en la eficiencia económica en la medida que se mejoren las relaciones y condiciones del trabajo; que en la construcción de ciudadanía la sociedad civil asuma un rol protagónico en la colocación del tema en las agendas nacionales y locales, lo mismo que lo utilicen para mejorar las intervenciones que realizan; y que los centros de generación del conocimiento y las competencias profesionales, como las universidades, promuevan la investigación, formación, intervención y el debate sobre nuevos tópicos del capital social, de tal suerte que orienten el rumbo que ha de seguirse en la utilización de esta categoría.

Pero mientras esto quizá suceda, primero debemos intentar descubrir el capital social que poseemos y cuidar que no se erosione, luego habrá que invertir en el mismo desde cada uno de los espacios vitales en que interactuamos en la cotidianeidad. La acción colectiva debe ser fortalecida con más y mejor socialización 
del capital social, pero desde el prisma crítico que enfatizamos al inicio, es decir como un activo más, como un instrumento para la mejora de los rendimientos de otras formas de capital y como un enfoque que no sustituye la intervención estatal en la procuración del bienestar social, ni mucho menos que pretenda borrar de la memoria histórica el origen de las desigualdades y la pobreza o que mediatice los conflictos sociales estructurales. Quedando a salvo la incidencia en los procesos de cambio y transformación social, quiero decir, sin perder de vista que lo más importante es remover las trabas que obstruyen el desarrollo humano, nos inscribimos entonces en la línea de que el capital social no sólo debe ser usado, sino institucionalizado y universalizado.

\section{REFERENCIAS BIBLIOGRÁFICAS ${ }^{11}$}

AGUIRRE, A. \& PINTO, M. (2006). Asociatividad, capital social y redes sociales. Revista Mad. No.15. Departamento de Antropología. Universidad de Chile. Acceso el 4 de junio de 2012. Disponible en: http://www.revistamad.uchile.cl/15/aguirre.pdf

ALBERDI, J. \& PÉREZ, K. (2006). Capital Social. Diccionario de Acción Humanitaria y Cooperación al Desarrollo. Universidad del País Vasco: HEGOA. Acceso el 4 de junio de 2012. Disponible en: http://dicc.hegoa.efaber.net/listar/mostrar/29

ALZATE ZULUAGA, M. L. (2008). Esbozo teórico de la acción política colectiva. Experiencias colectivas alternativas frente a las relaciones hegemónicas de dominación. Investigación y desarrollo vol. 16, $\mathrm{n}^{\circ} 2$. Universidad del Norte de Colombia. Acceso el 12 de junio de 2012. Disponible en:

http://ciruelo.uninorte.edu.co/pdf/invest_desarrollo/16-2/7_ Esbozo\%20teorico.pdf

ARBOLEDA, O. L., GHISO, A. M. \& QUIROZ, E. H. (2008). Capital social: revisión del concepto y propuesta para su reelaboración. Acceso el 23 de mayo de 2012. Disponible en: http:// www.udem.edu.co/NR/rdonlyres/EC45005D-4AEF-45E7A754-DB53DA62B8DD/7463/Conceptodecapitalsocial.pdf

11 Una dificultad fue no disponer de bibliografía más actualizada sobre tres palabras claves (politización, experiencias precursoras y relaciones de causalidad del capital social). Para esta publicación se actualizaron las búsquedas. 
ARRIAGADA, I. (2003). Capital Social; Potencialidades y limitaciones analíticas de un concepto. Red de revistas Científicas de América Latina y el Caribe, España y Portugal. UNAM, México. Acceso el 6 de octubre de 2012. Disponible en:

http://redalyc.uaemex.mx

ARRIAGADA I, (2005). Aprender de la experiencia. El capital social en la superación de la pobreza. Santiago de Chile. CEPAL. Acceso el 15 de mayo de 2012. Disponible en:

http://www.eclac.org/publicaciones/xml/2/23012/lcg2275e_ segudaparte.pdf

ATRIA, R. (2003). La dinámica del desarrollo del capital social: Factores principales y su relación con los movimientos sociales. Acceso el 18 de mayo de 2012. Disponible en: http:// www.eclac.cl/dds/noticias/noticias/2/11572/Atria.PDF

BANCO INTERAMERICANO DE DESARROLLO. (2003). Iniciativa Interamericana de Capital Social, Ética y Desarrollo. Acceso el 18 de mayo de 2012. Disponible en:

http://www.bvsde.paho.org/bvsacd/crics6/inbid.pdf

BANCO MUNDIAL. (2002). Grupo de expertos en capital social. Acceso el 18 de mayo de 2012. Disponible en: http://preval. org/documentos/00420.pdf

BENTOLILA, S. (2004). Capital Social ¿Negativo? Acceso el 12 de junio de 2012. Disponible en: http://wonkapistas.blogspot. com/2004/11/capital-social-negativo.html

BEVORT, A. (2007). El capital social y las teorías sociológicas. Breve historia intelectual del capital social. Universidad del País Vasco. Acceso el 18 de mayo de 2012. Disponible en: http://www.eustat.es/documentos/datos/CV07_02.pdf

DURSTON, J. (1999). Construyendo capital social comunitario. Una experiencia de empoderamiento rural en Guatemala. Serie de Políticas Sociales, No. 30 (LC/L1177), abril. Santiago: CEPAL.

DURSTON, J. (2000). ¿Qué es el capital social comunitario? Serie de Políticas Sociales. No 38. Santiago: CEPAL.

FIGUEROA HUENCHO, V. Capital social y desarrollo indígena urbano: Una propuesta para una convivencia multicultural. Los 
Mapuches de Santiago de Chile. Tesis doctoral. Acceso el 6 de octubre de 2012. Disponible en:

www.tdx.cat/.../1/TESIS_VERONICA_FIGUEROA_HUENCHO. pdf

FORNI, P., SILES, M. \& BARREIRO, L. (2004). Qué es el capital social y cómo analizarlo en contextos de exclusión social y pobreza en América latina. Estudios de casos en Buenos Aires, Argentina. Acceso el 6 de octubre de 2012, disponible en: http://www.econo.unlp.edu.ar/uploads/docs/capital_social_ en_exclusion_y_pobreza_jsri.pdf

GIL CALVO, E. (2006). El eclipse del capital social. Acceso el 29 de mayo de 2012. Disponible en: http://www.attacmadrid. org/d/7/060725133755.php

GORDON, S. (2006). Confianza, reciprocidad y asociatividad: ¿Relación indispensable para el desempeño institucional? Estudios Sociológicos XXIV: 71. México D.F. Acceso el 18 de mayo de 2012. Disponible en:

http://redalyc.uaemex.mx/pdf/598/59807105.pdf

GUTIÉRREZ SEPÚLVEDA, T. (2008). Revisión y aplicación del concepto de capital social. Santiago de Cali. Acceso el 18 de mayo de 2012. Disponible en:

http://www.slideshare.net/AndesBFP/revisin-y-aplicacin-delconcepto-de-capital-social

HERREROS VÁZQUEZ, F. (2005). Capital social y gobierno democrático. Fundación Alternativas. Acceso el 6 de octubre de 2012. Disponible en:

http://www.falternativas.org/laboratory/documentos/documentosde-trabajo/capital-social-y-gobierno-democratico

LIGHT, D., KELLER, S. \& CALHOUN, C. (1991). Sociología. (5ta. Edición). Santa Fe de Bogotá, Colombia: Presencia Ltda.

LORENZELLI, M. (2003). Capital social comunitario y gerencia social. VIII Congreso Internacional CLAD "Reforma del Estado y la Administración Pública", Panamá. Acceso el 18 de mayo de 2012. Disponible en:

http://unpan1.un.org/intradoc/groups/public/documents/CLAD/ clad0047525.pdf 
MÁRQUEZ ZÁRATE, M.A. (2009). El estado del arte del capital social comunitario. "Encrucijada" Tercer Número. Revista Electrónica del Centro de Estudios en Administración Pública de la Facultad de Ciencias Políticas y Sociales, UNAM. Acceso el 18 de mayo de 2012. Disponible en: http://ciid.politicas. unam.mx/encrucijadaCEAP/arts_n3_09_12_2009/art_ineditos3_3_marquez_zarate.pdf

MARTÍNEZ, R., SÁENZ, F. \& RUIZ, P. (2006). La generación de capital social en los parques científicos y tecnológicos. Acceso el 18 de mayo de 2012. Disponible en:

http://dialnet.unirioja.es/servlet/fichero_ articulo?codigo $=2476757$

MIRANDA, F. \& MONZÓ, E. (2003). Capital social, estrategias individuales y colectivas: el impacto de programas públicos en tres comunidades campesinas de Chile. Serie de Políticas Sociales (No. 67); CEPAL.

MONTESINOS SANTALUCÍA, V., SERRANO MARTÍNEZ, L., FERNÁNDEZ DE GUEVARA, J. \& FRANCISCO PÉREZ GARCÍA, F. (2005). La medición del capital social: Una aproximación económica. Bilbao: Fundación BBVA.

MONTORO ROMERO, R. (1997). Fundamentos teóricos de la política social. Acceso el 18 de mayo de 2012. Disponible en: http://www.uam.es/personal_pdi/economicas/rmontoro/ Mis\%20articulos/politicasocial.pdf

MUGARRA ELORRIAGA, A. (2005). El cooperativismo de Mondragón, en el Alto Deba, País Vasco. Ekonomias, No. 59, 2 do. Cuatrimestre.

NAVARRO, V. (2003). Crítica del concepto de capital social. En Sistema, Revista de Ciencias Sociales, No. 172. Madrid: Castalia.

PIURA, J. (2006). Metodología de la investigación científica: Un enfoque integrador. Managua: PAVSA.

PORTELA, M. \& NEIRA, I. (2002). Capital social: las relaciones sociales afectan al desarrollo. Colección Documentos, Instituto Internacional de Gobernabilidad de Catalunya. Acceso el 18 de mayo de 2012. Disponible en:

http://www.girona.cat/ccivics/docs/capital_social.pdf 
PORTES, A. (1998). Capital social: sus orígenes y aplicaciones en la sociología moderna.

Acceso el 6 de octubre de 2012, disponible en:

http://suburbioeducativo.files.wordpress.com/2011/07/ portes-capital_social-versic3b3n-en-espac3b1ol.pdf

PUTNAM, R. (2003). El declive del capital social. Barcelona: Galaxia Gutenberg (Círculo de Lectores).

PUTNAM, R. (2003). El declive del capital social. Acceso el 29 de mayo de 2012. Disponible en: http://es.wikipedia.org/wiki/ Robert_Putnam

QUIVY, R. \& CAMPENHOUDT, L.V. (2000). Manual de investigación en Ciencias Sociales. México DF: Limusa.

SÁNCHEZ, J.M. \& PENA, J.A. (2005). Actividad asociativa, confianza y generación de capital social: evidencia empírica. Ekonomiaz, No 59, 2do. Cuatrimestre, Barcelona.

SERRANO, C. (2001). Pobreza, capital social y ciudadanía. Acceso el 29 de mayo de 2012. Disponible en:

http://www.sitiosur.cl/publicacionescatalogodetalle.php?PID $=3337 \& d o c=Y \& l i b=Y \& r e v=Y \& a r t=Y \& d o c 1=Y \& v i d=Y \& a u t o r=\&$ coleccion=\&tipo=ALL\&nunico=15000034\#descargar

TORCAL, M. \& MONTERO, J.R. (2000). La formación y consecuencias del capital social en España. Revista española de Ciencia Política Vol. 1, No.2, abril de 2000. Acceso el 29 de mayo de 2012. Disponible en:

http://www.aecpa.es/uploads/files/recp/02/resumenes/03.pdf

UPHOFF, N. \& WIJAYARATNA, C. M. (2000). Beneficios demostrados del capital social: La productividad de las organizaciones campesinas de Gal Oya, Sri Lanka. Acceso el 8 de junio de 2012. Disponible en:

http://www.rimisp.org/boletines/bol2/social.html

VELAZCO, E., BLANCO, G. \& PACHECO, Y. (2009). Capital Social. Acceso el 17 de junio de 2012. Disponible en: http://capitalsocialsc.blogspot.com/

VITERI DÍAZ, G. (2006). Capital social y reducción de la pobreza. Acceso el 16 de mayo de 2012. Disponible en: http://www. monografias.com/trabajos-pdf/capital-social-reduccion-pobreza/capital-social-reduccion-pobreza.pdf 
WOOLCOCK, M. \& NARAYAN, D. Capital social: Implicaciones para la teoría, la investigación y las políticas sobre desarrollo. Acceso el 6 de octubre de 2012. Disponible en: http://redalyc. uaemex.mx 